\title{
Sa \\ Género y Cultura de Paz
}

\section{Introducción}

$1^{\text {a }}$ edición - Managua, Nicaragua: Sello Editorial Nos-Otros. 2017. 224 p.

N305.4 G327 ISBN 978-99964-40-00-7

Por Débora García-Morales ${ }^{1}$

\section{...Vamos, decime, contame \\ todo lo que a vos te está pasando ahora, \\ porque sino cuando está el alma sola llora \\ hay que sacarlo todo afuera, como la primavera \\ nadie quiere que adentro algo se muera \\ hablar mirándose a los ojos sacar lo que se puede afuera \\ para que adentro nazcan cosas nuevas}

(Soy Pan, Soy Paz, Soy Más. Mercedes Sosa/ Compuesto por Piero José)

El texto es un saludo a los 50 años de vida y trayectoria académica de la Universidad Politécnica de Nicaragua, (UPOLI) por parte del Instituto de Estudios de Género y el Instituto Martín Luther King. Ambos Institutos surgidos de la manifestación concreta de la paz y la equidad de género, que son valores explícitos en su política institucional.

Presentamos una compilación de artículos temáticos que resultan estratégicos para la compresión de un estado de situación en torno a la contemporaneidad de los estudios de género y la paz. La Paz, es una aspiración humana que en este siglo ha vuelto a ser relevante ante el asedio de la violencia y sus implicaciones para la vida de quienes se ven sometidos a padecerla por la historia regional de sus países, su condición de género, clase, etnia.

El campo fértil de los Estudios de Género y la Cultura de Paz impregnan un vasto acervo de líneas de investigación, artículos y textos. Los estudios de
Género han visibilizado cómo la diferencia sexual en procesos de socialización cultural, puede generar asimetrías de poder y exclusión. La cultura de la guerra se expresa dentro de las relaciones sociales que se producen en el patriarcado, este sistema legitima la asimetría social y el símbolo de la violencia. Una cultura de paz abraza el deseo de transformación y cambios que coadyuven al establecimiento de un orden social basado en la justicia para la igualdad; en medio de la diversidad de culturas que coexisten en nuestro Ethos humano.

El Ethos humano es un lienzo en el que se configuran fundamentos axiológicos para los principios de democracia, derechos humanos, justicia social, desarrollo sustentable, la economía para la vida y la igualdad entre hombres y mujeres. Los valores de la cultura de paz como la justicia, la igualdad, la solidaridad; nos trazan un camino hacia la historia reciente del país en búsqueda de un devenir histórico que permee la conciencia de un punto de partida para hacer las paces.

1 Teóloga, educadora. Directora del Instituto de Estudios de Género (IEG-UPOLI), Correo: genero@upoli.edu.ni. orcid.org/0000-0002-4609-6664 


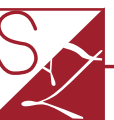

El libro es un aporte desde las nuevas epistemologías, de género y de la paz. En el centro de estas miradas están la construcción de relaciones justas y la deconstrucción de los órdenes injustos que hacen violencia. Autoras como Carmen Magallón, Marcela Lagarde, Elsa Támez, Consuelo Ruiz, Mercedes Fernández, Aura Violeta Aldana Saraccini, Soren Chamorro, María Martha Zúñiga Acevedo, Manuela Mesa, Martha Zapata, también Orlando Núñez y Frederick W. Lange; nos invitan a leer con avidez los ejes temáticos que han sido organizados para guiar nuestra lectura interna.

\section{El primer tema Mujer}

y Cultura nos introduce a la paz con rostro de mujer y sus implicaciones para la vida y la herencia generacional. En este eje nos encontramos miradas del pasado que siguen teniendo vigencia para el presente, en el desarrollo de la democracia. La democracia como acción y base de la ciencia democrática, es el punto de llegada para el binomio ciudadanía y mujer, un rasgo sin el cual no podríamos entender el legado femenino civilizatorio.

Un segundo tema es el de la violencia de género. Eje relevante para comprender la demanda de justicia de las mujeres. La violencia hacia las mujeres es el drama del siglo

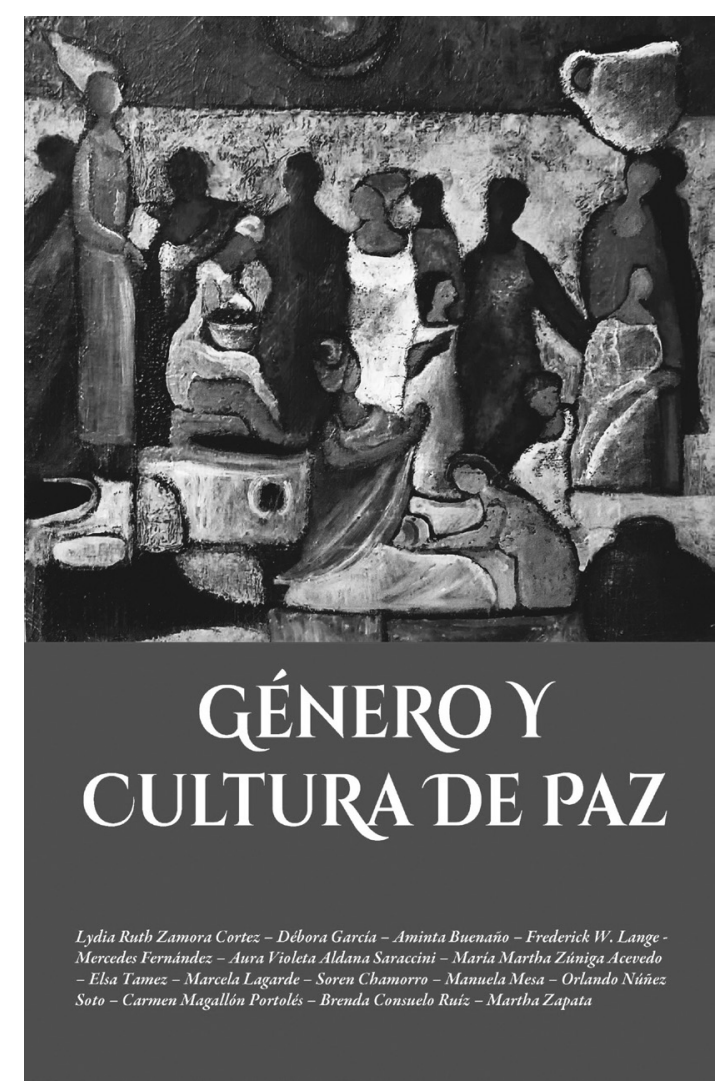

las relaciones entre los hombres y las mujeres. Un acercamiento al tema de Género, Biblia y Cultura de Paz es vital; dado que la religión cristiana aporta a la reflexión sobre la dimensión de la dignidad humana.

Un cuarto tema desarrolla una comprensión acerca de la identidad de género. Los subtemas sobre nuevas masculinidades, el género desde el relativismo cultural, los enfoques de género en los acuerdos de paz en Colombia nos permiten ahondar en el nuevo esquema ofrecido en la agenda de Género y Cultura de Paz. Los logros de paz en Colombia son un hito por reconocer el impacto de la guerra y la violencia en la vida de las mujeres. Así como el desmantelamiento de la violencia como signo patriarcal, es esperanzador para los hombres y mujeres en esta presente generación.

El último tema nos apunta a la conciencia de la casa común, al reconocimiento de la educación como punto de llegada y eje transformador.

Los ejes temáticos son un símbolo del cambio de época que vivimos, estamos ante nuevos sistemas de cognición al que apuntan la reflexión de lo vivido, a la búsqueda de nuestras huellas sociales.

Dispónganse estimadas XXI que pesa sobre la estructura patriarcal de las relaciones de poder. Abordar este hecho social de graves consecuencias, evidencia que llevamos más de cuatro décadas de resistencia social, y qué aún declaramos que esperamos que la justicia no se retarde por los mecanismos de reformas a leyes integrales.

El tercer tema es el eje hermenéutico de la perspectiva bíblica, base en el discernimiento para cambios sustantivos de los estereotipos de asiduas lectoras y lectores a disfrutar el texto escrito. Animamos al cuerpo docente de las asignaturas de Cultura de Paz y de Género en la Vida Cotidiana, a leer con compromiso y descubrir claves de lectura para la materialización de la enseñanza aprendizaje. Este libro, nos ofrece una mirada con profundidad sobre el legado de las mujeres a la Paz y el aporte de hombres a esta reflexión, para el bien común y la defensa de la vida. 